\title{
AN APPRENTICESHIP IN MASK MAKING: SITUATED COGNITION, SITUATED LEARNING, AND TOOL ACQUISITION IN THE CONTEXT OF CHINESE DIXI MASK MAKING
}

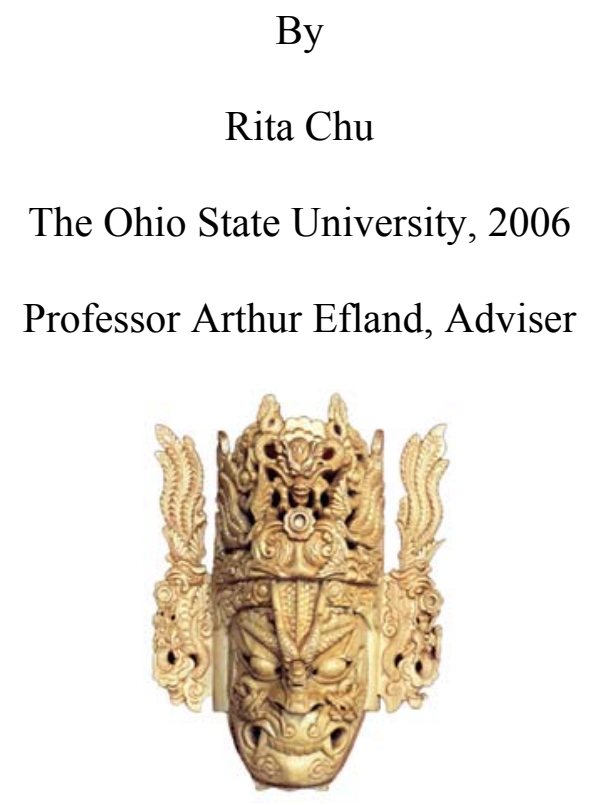

This study unmasks Chinese Dixi mask makers, who have been masked in Chinese history for centuries. Instead of writing their history, this study tells their mental stories. Instead of understanding them through interview, this study assumes an apprentice's role to learn a mask maker's way of thinking and his community's worldview. This apprenticeship, as a situated learning in non-Western art, is analyzed in retrospective light. During the apprenticeship, the situation occurred while learning how to use mask making tools serves as the point of departure, where the discussion of situated cognition and technology as psychological tools begins. 


\section{INTRODUCTION}

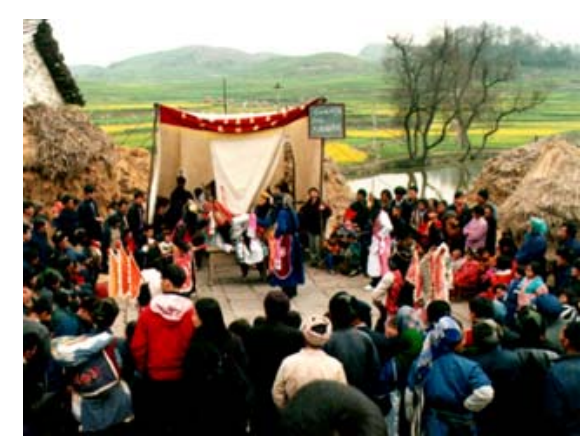

(A snapshot of the Dixi mask ritual performance)

Dixi, actually called "Dancing of the Gods" by the people of Anshun City in Guizhou, China, refers to a particular type of Chinese mask ritual, in which masks are worn and stories are acted out. In its ritual performance, the wearing of masks symbolizes the arrival of the gods, and the performed stories represent the gods in action. As the ritual proceeds and the story unfolds, the crowd swarms in to join the union of heaven and earth. Such a union echoes with the mixed purposes of the ritual performance, which are to thank the gods on the one hand, and to please the gods (as dramas please humans) on the other. Since the gods are thanked and pleased, humans are therefore blessed. The audience is simultaneously entertained.

Besides the performance aspects, the Dixi scripts, the lyrics chanted by the masked performers in the ritual, are not only culturally significant but also educational. Written in highly literal Chinese language and transcribed by each mask performer, the lengthy Dixi script is actually an educational medium that eliminates illiteracy among the local people, disseminates knowledge, and transmits traditions. 
The important role that Dixi plays in the life of Anshun people is further heightened by the fact that in Anshun, television is not yet the center of daily entertainment and seasonal rituals are still sincerely observed. Dixi is more than just a type of sacred ritual. It truly stands for who the Anshun people are and what they believe in, while it sustains their traditions and values.

Although Dixi belongs to the Chinese mask ritual family that consists of many different types of mask rituals, Dixi differs from all others both in the intricacy of the masks and the type of the performance stories (i.e., the performance script). Dixi masks are carved out according to the descriptions of the characters depicted in the performance story. The story is in fact one of the variant versions of a certain Chinese popular classic, such as such as Romance of the Three Kingdoms, or The Campaign to the West. The relation between the performance story and the popular classic indicates that Chinese classics are the resource for the Dixi stories, which subsequently become the sources for the Dixi mask making. The sequence, from the verbal to the visual, from classics to rituals, makes me wonder: why are they connected this way? This question finally draws me into a search for the stories hidden behind the Dixi masks, namely, the underlying cognition of Dixi mask making.

How do mask makers translate the verbal into the visual? How do they embody performance stories in the masks? How are meanings conveyed through Dixi masks? And, what are the meanings conveyed? In order to answer these questions, I situated myself within the mask making learning system (i.e., apprenticeship) and I became an apprentice to a Dixi mask maker, Mr. Yang. 
During my apprenticeship, I conducted three consecutive activities. They are: (a) observing and video-taping some episodes of Dixi mask performance, (b) videotaping one of Mr. Yang's mask making process as an example of the general procedure of Dixi mask making, and (c) experiencing the mask making process myself.

After the second activity, in which I observed and documented the maskmaking process, I thought I perfectly understood what mask making was all about. However, as soon as I raised the mask making tools and began making a mask with my own hands, my freshly learned "understanding" silently slipped away. I was purely stunned. In front of a block of wood for a mask to be made, I could do nothing but sit still. My mind was blank; my thought was frozen. I simply did not know what to do.

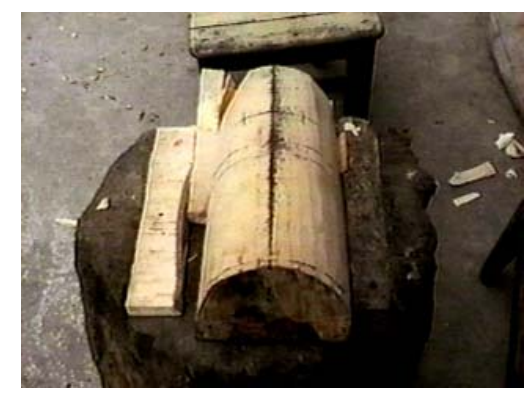

After 30 seconds or so, of not knowing what to do or where to start, I politely asked my master Mr. Yang if he could draw me some lines as my guidance in dealing with the intact block of wood that was taunting me. He then laughed and said: "How can you use two dimensional lines to guide three dimensional work? Many situations will happen; those lines won't help." His answer made me feel embarrassed, humiliated, and finally delighted.

The mask maker's notion of "situations" challenged such academically imbued concepts as "guidelines" and "lesson plans." In contrast to academia's planned 
approach to teaching and learning, the mask maker's "situated teaching" seemed ad hoc, while planned instructions seemed more reliable. But, how can teaching take place in an ad hoc situation, as mask makers have been doing for many centuries? Is there any planning involved, or is it simply impossible to plan at all?

What did the mask maker really mean by "situations"? How do "situations" guide the mask making? Likewise, can artistic cognition be learned or taught?

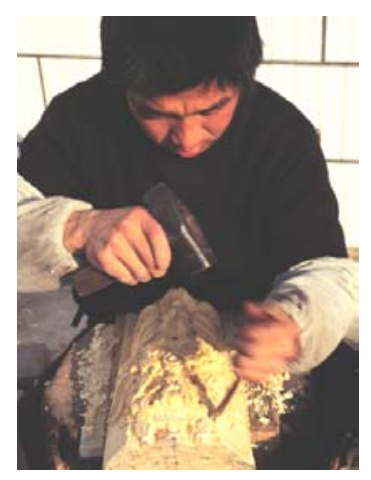

\section{SITUATED COGNITION: VYGOTSKY'S SOCIOCULTURAL VIEW OF COGNITION}

With an attempt to understand what the mask maker meant by "situations" and how seemingly ad hoc "situations" guided his mask making, theories on situated cognition, which include Vygotsky's and neo-Vygotskians' sociocultural psychological theories, are extensively reviewed in this study. As Vygotsky was much inspired by Marx and Engels, Marxism is also discussed so as to better contextualize the literature reviewed for the study. These theories serve as analytical tools to decipher thinking, learning and teaching in the context of Chinese Dixi mask making, whereas Efland's integrated lifeworld theory provides a conceptual bridge for this study to link the study's theoretical discussions with its applications to teaching and learning in the arts. 
Situated cognition refers to not only the ideas that thinking is bounded and knowing is situated but also a recognition of the process itself, which might give rise to new ideas or new ways of thinking. These newly emerged elements woven together with the context as a whole situate cognition in an unpredictably way. Borrowing Dewey's (1938) phrase, it is "the contextual whole" that situates cognition.

On the other hand, humans are no longer born into a world that has no civilization. Most of the human activities are facilitated by signs (e.g., language and art) and tools (e.g., computers and mask making tools). These signs and tools facilitate mind grow, while growing into mind. They situate cognition by facilitating it. Therefore, Vygotsky called them "psychological tools." As the mask making tools are psychological tools, so is computer technology. What mask making tools are to the mask making community, computer technology is to the modern society. Tools facilitate and situate individual mind; technology facilitates and situates the development of the society. The acquisition of tools, as well as technology, is in fact a process of enculturation.

Dixi mask making is a process of the mask maker's imaginative cognition because mask making is to materialize the divine images socially constructed by the mask ritual community. While divine images belong to the immaterial realm, mask making is material production. How do mask makers translate these mental images into concrete masks? Where do mask symbols come from? And, how can this mental representation process be taught and acquired? Answers to these questions might help art educators to bestow students with cognitive tools to foster their imagination. 


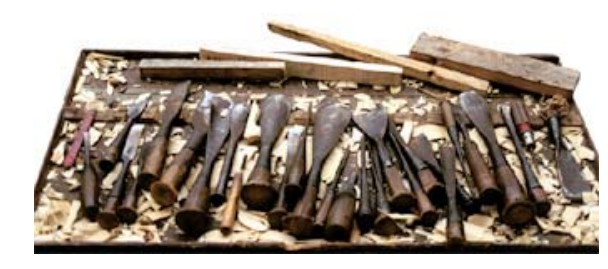

\section{METHODOLOGY AND PURPOSE}

Experimentally, this study conducts fieldwork prior to the perfection of the research proposal for three reasons: (a) the research possibility is only once a year. Although the mask ritual performance were held twice a year, but only would the one held during the Chinese New Year be formally performed, and which usually lasted for half a month; (b) it was a complicated and difficult political process. The Chinese government supervised all scholarly activities in Guizhou, China. I went through the hoops and finally received the officially approved research permission for beapprenticing to the Chinese Dixi mask maker, Mr. Yang. The hard-earned approval from the Chinese government was not only too precious to give up but also too scary and unpredictable to ever try again; (c) had not my current, creative advisor, Dr. Efland said: "It would be interesting to see how it goes retrospectively," I wouldn't dared to have done so. Now, I am glad that I did. I am most thankful to his creative spirit.

Situated learning, the methodology of this study, is referred to "learning in situ," or "learning by doing." the meaning better defined by (Lave and Wenger, 1991). In so doing, it is hoped that mask maker's thinking is unraveled in his most common activity, interaction between cognition and the environment can be perceived, and my research insight is gained through experience, not solely from observation. 
Besides as the methodology of this study, Situated learning is also "an analytical viewpoint on learning, a way of understanding learning" (Lave and Wenger, 1991, p. 40). To me, research is a process of learning and researchers are learners. I saw myself more as a learner than a researcher; I was learning about how mask makers think within the context of mask making, not merely investigating as an on-looking researcher. This apprenticeship is also an example of "legitimate peripheral participation," as Lave and Wenger redefined situated learning, as I was legitimized by the Chinese government first and then gradually legitimized by the people of the mask making community. Geographically, I moved from the United States to the Southern China. Conceptually, I moved from being a cultural outsider to a partially participating apprentice. It is fair to say that to study a culture, the researcher is like an apprentice, who moves from the peripheral to the core of the culture while being legitimized by the subject and his or her community (Lave and Wenger, 1991).

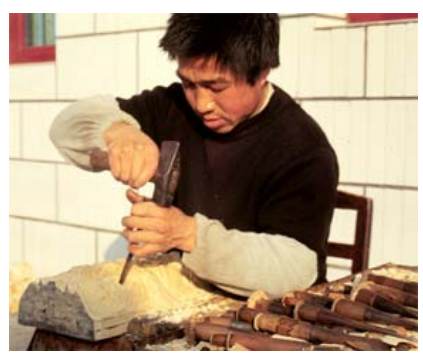

\section{SIGNIFICANCE}

By unmasking mask makers, this study gives a different interpretation of Chinese history. It also adds a hitherto-undocumented historical page of Chinese mask makers to Chinese history so that mask makers' contribution to the Chinese tradition over the centuries can be recognized. On the other hand, by taking a cognitive approach 
to mask maker's cognition, this study presents the mentality of non-academic artists, who are sometimes referred to as craftsmen. Should the notion of craftsmanship be better understood herein, this study serves its purpose.

After all, this research journey, with much fumbling and tumbling on the road, to me, is more significant than the answers initially set out for. This journey made me realize that the process of research can be as significant as the answers to the research questions; the unplanned can be as important as the planned; the scientific approach is a style, not intelligence itself. By presenting this research journey, I hope this study demonstrates that learning is a growing process, which is dynamic, rather than static; the reality of research is as situated as this study is investigating.

This study also intends to contribute to Chinese history where mask makers are absent so far. Despite the fact that the Chinese mask makers have been contributing to transmitting Chinese beliefs and values with their own art and skills for as long as the history of the Chinese mask, however, there has not been much written about them. By telling their stories, it is hoped that this study gives Dixi mask makers a recognize of their knowledge, skills, and their contribution to Chinese culture in their colorful and silent way.

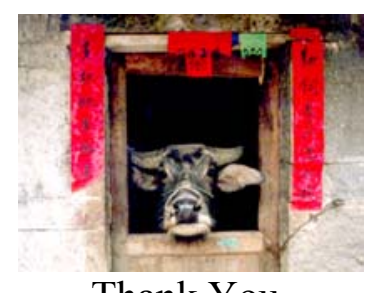

Thank You. 